\title{
Shared environments: a multilevel analysis of community context and child nutritional status in Bangladesh
}

\author{
Daniel J Corsi ${ }^{1, *}$, Clara K Chow ${ }^{1}$, Scott A Lear ${ }^{2}$, M Omar Rahman ${ }^{3}$, SV Subramanian ${ }^{4}$ \\ and Koon K Teo' \\ 'Population Health Research Institute, McMaster University and Hamilton Health Sciences, 237 Barton Street \\ East, Hamilton, Ontario L8L 2X2, Canada: ${ }^{2}$ Department of Biomedical Physiology and Kinesiology, Simon Fraser \\ University, Vancouver, British Columbia, Canada: ${ }^{3}$ Centre for Health, Population and Development, Independent \\ University, Bangladesh, Baridhara, Dhaka, Bangladesh: ${ }^{4}$ Department of Society, Human Development, and \\ Health, School of Public Health, Harvard University, Boston, MA, USA
}

Submitted 31 March 2010: Accepted 14 October 2010: First published online 11 February 2011

\begin{abstract}
Objective: The goal of the present study was to examine the influence of community environment on the nutritional status (weight-for-age and height-forage) of children (aged 0-59 months) in Bangladesh. In addition, we tested the association between specific characteristics of community environments and child nutritional status.

Design: Cross-sectional survey.

Setting: The data are from the nationally representative 2004 Bangladesh Demographic and Health Survey.

Subjects: Respondents were ever-married women (aged 15-49 years) and their children ( $n$ 5731), residing in 361 communities. Child nutritional outcomes are physical measurements of weight-for-age and height-for-age in SD units. We considered the following attributes of community environments potentially related to child nutrition: (i) community water and sanitation infrastructure; (ii) availability of community health and education services; (iii) community employment and social participation; and (iv) education level of the community. Results: Multilevel regression analysis showed that the spatial distribution of maternal and child covariates did not entirely explain the between-community variation in child nutritional status. The education level of the community emerged as the strongest community-level predictor of child height-for-age (highest $v$. lowest tertile, $\beta=0 \cdot 18(\operatorname{se~} 0 \cdot 07)$ ) and weight-for-age (highest $v$. lowest tertile, $\beta=0 \cdot 21$ (se $0 \cdot 06)$ ). In the height-for-age model, community employment and social participation also emerged as being statistically significant (highest $v$. lowest tertile, $\beta=0 \cdot 13(\mathrm{sE}=0 \cdot 06)$ ).

Conclusions: The community environment influences child nutrition in Bangladesh, and maternal- and child-level covariates may fail to capture the entire influence of communities. Interventions to reduce child undernutrition in developing countries should take into consideration the wider community context.
\end{abstract}

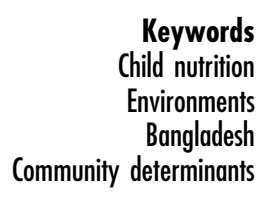

Keywords Environments

Bangladesh Community determinants
Child undernutrition leading to suboptimal growth in early life continues to be highly prevalent in South Asian countries $^{(1,2)}$. In Bangladesh, two out of every five children suffer from moderate-to-severe underweight ${ }^{(3)}$, falling at least 2 SD below the median weight-for-age of the WHO Child Growth Standards ${ }^{(4)}$. In addition to facing an elevated risk for infectious diseases ${ }^{(1,5)}$, undernourished children face impaired cognitive and social development, poor school performance, reduced physical work capacity and the development of long-term cardiovascular and metabolic conditions ${ }^{(6-11)}$. Despite the importance of early child nutrition for survival and long-term development, the international nutrition community has faced many challenges in the development of a consensus on priorities, actions and strategies to combat the enduring problem of child undernutrition ${ }^{(6,12,13)}$.

More than 30 years ago, the 1978 Alma-Ata Declaration $^{(14)}$ envisioned the provision of comprehensive, universal and affordable health-care services in all countries through community-based primary health care (PHC). The PHC model emphasized the delivery of care by community workers with a focus on prevention and on the underlying determinants of maternal and child health and nutrition, including the environment (community), agriculture, education and livelihoods ${ }^{(15)}$. The process of local community involvement and improvement of the 
social environment was challenging and inconsistently applied $^{(15,16)}$. Instead, a selective programme of PHC with a focus on the implementation of a few key interventions deemed to be most cost-effective and epidemiologically important was generally favoured in many developing countries $^{(17)}$. Key interventions aimed at improving child undernutrition implemented over this period largely focused on maternal and child-level determinants, including low birth weight ${ }^{(18-20)}$, maternal undernutrition ${ }^{(21,22)}$, vitamin $\mathrm{A}^{(23,24)}$, Fe and $\mathrm{Zn}$ deficiencies ${ }^{(1,25,26)}$, infectious diseases $^{(27,28)}$, feeding practices, maternal education and health-seeking behaviour ${ }^{(29-32)}$.

More recently, renewed interest in the importance of community-based PHC, use of community health workers and increased recognition of the social determinants of health have highlighted the ongoing relevance of the AlmaAta principles for maternal and child health in developing countries ${ }^{(15,33,34)}$. Landmark cross-country research by Smith and Haddad ${ }^{(35,36)}$ has implicated basic contextual, environmental and societal factors (including health environments, women's education and status and food availability) as important determinants of child nutrition in developing countries. The potential strength of these underlying determinants of child nutrition was first raised at Alma-Ata in 1978 and later incorporated into the framework on child undernutrition developed by UNICEF in $1991^{(14,37)}$. Although recent studies have shown a growing recognition that mothers and children reside in communities and that shared environmental contexts may be of key importance in improving child nutrition ${ }^{(38-40)}$, we are not aware of any corresponding research that has systematically quantified and investigated the influence of multiple aspects of the community environment on child nutritional status.

The present paper extends previous research by examining the amount of variation in child nutritional status in Bangladesh that is attributable to communities, with a focus on specific aspects of the community environment that may account for such variation ${ }^{(41)}$. The Bangladesh Demographic and Health Survey (BDHS) ${ }^{(42)}$ reported moderate evidence of between-community variation in child weightfor-age ( $8 \%$ of variation attributed to communities) and height-for-age ( $9 \%$ of variation attributed to communities). In the present study, we tested whether community water and sanitation infrastructure, availability of community health and education services, community employment and social participation, and education level of the community explained between-community variation in child nutritional status using a nationally representative sample of children in Bangladesh.

\section{Methods}

\section{Sample}

In 2004, a household survey was conducted in Bangladesh to obtain detailed information on maternal and child health and nutrition as part of the demographic and health survey (DHS) programme ${ }^{(42)}$. The 2004 BDHS used a nationally representative multi-stage sample design, stratified according to urban and rural areas. The primary sampling unit was defined as census enumeration areas, based on the 2001 census. We have used the term community to describe these small areas, which comprised around 100 households. The 2004 BDHS systematically selected a sample of 10811 households from 361 communities, with a target of thirty households per community. Among the selected households, 10500 (99.8\%) were contacted successfully. All ever-married women aged 15-49 years residing in contacted households were invited to participate in the survey, and 11440/11601 (98.6\%) of eligible women completed an interview ${ }^{(42)}$.

The BDHS identified 6424 children younger than 5 years of age in the sampled households. In order to capture continuing influences of the community environment on child nutritional status, we excluded 571 children (8.8\%) who did not permanently reside in the community in which they were sampled. An additional $2 \cdot 1 \%$ of the sample had missing information on covariates and were excluded from analyses, which yielded a final sample for the present analysis of 5731 children under the age of 5 years and their mothers.

\section{Outcome measures}

Weight and height measurements for children (aged 0-59 months) were obtained by trained data collectors, using solar-powered scales and adjustable measuring boards, according to the standard DHS fieldwork protocol ${ }^{(42)}$. The measured weights and heights of children were converted to weight-for-age and height-for-age SD units (Z-scores) using the WHO Child Growth Standards ${ }^{(4)}$. These measures are routinely analysed to provide assessment of child nutritional status ${ }^{(2)}$.

\section{Assessment of community environment}

Data collected in the 2004 BDHS occurred at the individual, household and community levels. Communitylevel data collection and community service availability assessments were carried out in December 2003, immediately before individual- and household-level data collection processes, which were completed between January and May $2004^{(42)}$. In the present study, we used each data source to assess the community environment according to four specific characteristics, which are described below. We operationalized each community characteristic in tertiles (low, moderate and high) in order to allow for the possibility of non-linear relationships with child nutrition.

'Community water and sanitation infrastructure' is based on the household-level questionnaire and represents the proportion of households within each community that reported being supplied with piped drinking water and modern toilet facilities. 
'Availability of community health and education services' was defined using data from the communitylevel questionnaire. Distances to educational facilities (primary and secondary schools) and health-care services (hospitals, primary care facilities, private and nongovernmental organization (NGO) clinics) were reported to survey interviewers by a group of knowledgeable informants (community officials, teachers or local leaders) identified in each community ${ }^{(42)}$. Informants reported the distance to services available in their communities as the approximate distance (in $\mathrm{km}$ ) from the centre of their community to the facility. To ensure the validity of these self-reported measures, fieldworkers randomly checked a subsample of the reported distances. Previous DHS validation studies have documented good accuracy using this methodology ${ }^{(43)}$. The quality of service facilities was not assessed in the survey. Information on all community-level services was combined into a single variable using principal component analysis, with communities reporting shorter distances to services being considered to have better community service availability.

'Community employment and social participation' was defined using individual responses from female survey respondents and their husbands and aggregated to the community level. Community social participation came from the proportion of female respondents (husbands of survey respondents were not asked about social participation) who were members of at least one of six possible organizations, including Grameen Bank, mother's club and Bangladesh Rural Advancement Committee (a community-based NGO). Community employment was based on the proportion of respondents' husbands who were employed outside the agricultural sector, as an indicator of community economic development. Women's employment was not included as a community-level characteristic, as a majority of women (82\%) were not currently working at the time of the survey ${ }^{(42)}$. Social participation for women and employment for men were combined in a simple average and aggregated to the community level to represent the level of community employment and social participation.

The 'education level of the community' was specified as the average number of years of education of all residents of the community over the age of 15 years. These data came from the household questionnaire, which included a listing of all members of the household, their age and number of years of education, and covered 34910 individuals in the 361 communities (mean: 61 individuals per community). The mean number of years of education of our sample was about $4 \cdot 2$ years.

Communities were further classified according to the type of residential environment (urban centre, small city, town or rural area) and geographical region of Bangladesh (Barisal, Chittagong, Dhaka, Khulna, Rajshahi or Sylhet).

\section{Individual-level covariates}

We included several individual socio-economic and demographic variables as covariates in our analyses ${ }^{(44)}$ : child's age and gender, preceding birth interval, early breast-feeding, recent illness, mother's education, father's education, mother's age at birth, mother's BMI, household socio-economic status (SES) and household food security. Preceding birth interval was classified as 0-23, $24-47$ and $\geq 48$ months. A binary illness variable indicated whether the mother reported an incidence of fever, cough or diarrhoea in the previous 2 weeks. Mother's and father's education was defined in terms of the following categories: no formal education, primary education, secondary education and higher than secondary education. Maternal age at birth was measured in years. Mother's BMI $\left(\mathrm{kg} / \mathrm{m}^{2}\right)$ was calculated from the measured heights and weights of survey participants. Household SES was measured by an index derived from the education of the head of the household, as well as from dwelling characteristics and ownership of consumer goods and assets ${ }^{(45,46)}$. Assetbased indices are routinely used as measures of wealth or SES, and have been validated in several countries ${ }^{(45-47)}$. Household food consumption during the past year, a basic measure of food security, was based on a single question in the BDHS asking whether the household had sufficient food throughout the previous year or if there was an occasional or continuous deficit (or surplus) of food.

\section{Analysis}

Descriptive statistics were calculated and mean weightfor-age and height-for-age of children were examined across individual- and community-level variables using the STATA statistical software package version $10 \cdot 0$ (StataCorp., College Station, TX, USA). Our analytical approach used a multilevel conceptual and methodological framework and was conducted in two steps ${ }^{(48)}$. First, we examined the overall effect of communities on child nutritional status by specifying a two-level random intercepts linear model, composed of children (level 1) nested in communities (level 2) ${ }^{(49,50)}$. Second, we extended this model by including the specific community exposures under study, which were hypothesized to account for between-community differences in child nutrition ${ }^{(41)}$. A total of six models were specified for each outcome (child weight-for-age and height-for-age $Z$-score). All models were estimated using MLwiN statistical software version $2 \cdot 20$ (Bristol, UK) ${ }^{(51)}$, and included random intercepts for each community and parameters for the SD of individualand community-level errors ${ }^{(52)}$.

The first model estimated (model 1) was an unconditional model, which examined the average weight-for-age and height-for-age of children assessed for the amount of variation across communities. From this model, betweencommunity variation was summarized using the 'intra-class correlation', or the relative value of the community-level variance to total variance, and was expressed as a percentage 
from $0 \cdot 0$ to $100 \cdot 0^{(49,52)}$. In model 2 , we added individuallevel covariates to model 1 , and in model 3 we added community-level covariates to model 2. Models 2 and 3 re-estimated the community-level variance, adjusted for 'compositional' (individual-level) characteristics of the communities (in model 2) and further adjusted for 'contextual' (community-level) variables (model 3). The intra-class correlation estimates of community-level variance obtained from these models indicated the extent to which community-level variation in child weight and height persisted over and above that which could be attributed to observed individual-level factors (model 2) and observed communitylevel environmental factors (model 3).

The next set of estimated models tested the association between characteristics of the community environment and child weight- and height-for-age. First, a separate multilevel model was fitted for each outcome specifying one of four community-level characteristics (community water and sanitation infrastructure, availability of community health and education services, community employment and social participation, and level of community education) but no individual-level predictors (model $4 \mathrm{~A}-\mathrm{D})$. To each of these models, the matrix of individuallevel covariates was added (model 5A-D). The primary interest of these models was the association between child nutritional status and a specific aspect of the community, i.e. community water and sanitation infrastructure, before (model 4) and after (model 5) the model was adjusted for individual-level compositional characteristics of the community. The final model (model 6) included all community-level and individual-level covariates and was equivalent to model 3 , although the interest here was in examining the mutually adjusted coefficients for community-level environmental characteristics.

\section{Results}

The sample for analyses comprised 5731 children (aged 0-59 months) from 361 communities (seventeen from urban centres, twenty-three from small cities, eighty-two from towns and 239 from rural areas), with an average of sixteen children per community. The distribution of sample characteristics and the average height-for-age and weight-for-age across the characteristics are presented in Table 1 . No between-community differences in child-level demographics (age and sex) were observed. Overall, the average height-for-age and weight-for-age of children were -1.9 and $-1 \cdot 8$, indicating that the sample of children was 1.9 and $1.8 \mathrm{sD}$ below the WHO reference population in height and weight, respectively.

Figure 1 presents the average weight-for-age and height-for-age of children across tertiles of each community characteristic. Descriptively, these figures indicated a trend of increasing child nutritional status across increasing levels of community water and sanitation infrastructure,
Table 1 Sample characteristics and average weight-for-age and height-for-age of 5731 children aged 0-59 months in the 2004 Bangladesh Demographic and Health survey

\begin{tabular}{|c|c|c|c|c|}
\hline \multirow[b]{2}{*}{ Characteristics } & \multicolumn{2}{|c|}{$\begin{array}{c}\text { Weight-for-age } \\
\text { (Z-score) }\end{array}$} & \multicolumn{2}{|c|}{$\begin{array}{l}\text { Height-for-age } \\
\text { (Z-score) }\end{array}$} \\
\hline & $\%$ & Mean & $\%$ & Mean \\
\hline Overall & $100 \cdot 0$ & $-1 \cdot 8$ & $100 \cdot 0$ & $-1 \cdot 9$ \\
\hline \multicolumn{5}{|l|}{ Child's age (months) } \\
\hline $0-6$ & $11 \cdot 7$ & $-1 \cdot 3$ & $11 \cdot 6$ & $-1 \cdot 0$ \\
\hline $7-11$ & $7 \cdot 3$ & -1.5 & $7 \cdot 3$ & $-1 \cdot 3$ \\
\hline $12-23$ & $19 \cdot 8$ & $-1 \cdot 8$ & $19 \cdot 7$ & $-2 \cdot 0$ \\
\hline 24-35 & $20 \cdot 8$ & $-1 \cdot 9$ & $20 \cdot 7$ & $-2 \cdot 2$ \\
\hline $36-47$ & $20 \cdot 3$ & $-1 \cdot 9$ & $20 \cdot 4$ & $-2 \cdot 2$ \\
\hline $48-59$ & $20 \cdot 1$ & $-2 \cdot 0$ & $20 \cdot 3$ & $-2 \cdot 1$ \\
\hline \multicolumn{5}{|l|}{ Child's sex } \\
\hline Boy & $50 \cdot 8$ & $-1 \cdot 8$ & $50 \cdot 8$ & $-2 \cdot 0$ \\
\hline Girl & $49 \cdot 2$ & $-1 \cdot 8$ & $49 \cdot 2$ & $-1 \cdot 9$ \\
\hline \multicolumn{5}{|l|}{ Preceding birth interval (months) } \\
\hline $0-23$ & $38 \cdot 3$ & $-1 \cdot 8$ & $38 \cdot 4$ & $-1 \cdot 9$ \\
\hline $24-47$ & $33 \cdot 8$ & -1.9 & $33 \cdot 7$ & $-2 \cdot 1$ \\
\hline $48 \ddagger$ & $28 \cdot 0$ & $-1 \cdot 6$ & $27 \cdot 9$ & $-1 \cdot 7$ \\
\hline \multicolumn{5}{|l|}{ Child had a recent illness } \\
\hline Yes & $54 \cdot 9$ & $-1 \cdot 8$ & $54 \cdot 9$ & $-1 \cdot 9$ \\
\hline No & $45 \cdot 1$ & $-1 \cdot 7$ & $45 \cdot 1$ & $-2 \cdot 0$ \\
\hline \multicolumn{5}{|l|}{ Mother's BMI $\left(\mathrm{kg} / \mathrm{m}^{2}\right)$} \\
\hline$<18.5$ & $36 \cdot 9$ & $-2 \cdot 1$ & $36 \cdot 9$ & $-2 \cdot 2$ \\
\hline $18 \cdot 5-24 \cdot 9$ & $57 \cdot 0$ & $-1 \cdot 7$ & $56 \cdot 8$ & $-1 \cdot 9$ \\
\hline$\geq 25 \cdot 0$ & $6 \cdot 2$ & $-1 \cdot 0$ & $6 \cdot 3$ & $-1 \cdot 2$ \\
\hline \multicolumn{5}{|l|}{ Mother's education } \\
\hline No education & $37 \cdot 4$ & $-2 \cdot 0$ & $37 \cdot 3$ & $-2 \cdot 2$ \\
\hline Primary & $31 \cdot 5$ & $-1 \cdot 9$ & $31 \cdot 6$ & $-2 \cdot 1$ \\
\hline Secondary & $25 \cdot 7$ & -1.5 & $25 \cdot 6$ & $-1 \cdot 6$ \\
\hline Higher & $5 \cdot 5$ & -0.9 & $6 \cdot 6$ & -0.9 \\
\hline \multicolumn{5}{|l|}{ Household SES } \\
\hline Low & $34 \cdot 9$ & $-2 \cdot 1$ & $34 \cdot 9$ & $-2 \cdot 3$ \\
\hline Mid & $32 \cdot 9$ & $-1 \cdot 8$ & $32 \cdot 9$ & $-2 \cdot 0$ \\
\hline High & $32 \cdot 2$ & $-1 \cdot 4$ & $32 \cdot 2$ & $-1 \cdot 5$ \\
\hline \multicolumn{5}{|l|}{ Household food security } \\
\hline Deficit entire year & $13 \cdot 2$ & $-2 \cdot 2$ & $13 \cdot 1$ & $-2 \cdot 4$ \\
\hline Sometimes deficit & $37 \cdot 3$ & -1.9 & $37 \cdot 3$ & $-2 \cdot 1$ \\
\hline Not deficit, without surplus & $35 \cdot 3$ & $-1 \cdot 7$ & $35 \cdot 3$ & $-1 \cdot 8$ \\
\hline Not deficit, have surplus & $14 \cdot 3$ & $-1 \cdot 4$ & $14 \cdot 3$ & $-1 \cdot 5$ \\
\hline \multicolumn{5}{|l|}{ Type of community environment } \\
\hline Large city, capital & $3 \cdot 7$ & $-1 \cdot 6$ & $3 \cdot 7$ & $-1 \cdot 7$ \\
\hline Smaller city & $5 \cdot 7$ & $-1 \cdot 8$ & $5 \cdot 7$ & $-1 \cdot 9$ \\
\hline Town & $20 \cdot 8$ & $-1 \cdot 6$ & $21 \cdot 0$ & $-1 \cdot 7$ \\
\hline Countryside & $69 \cdot 8$ & $-1 \cdot 9$ & $69 \cdot 7$ & $-2 \cdot 0$ \\
\hline \multicolumn{5}{|l|}{ Division of residence } \\
\hline Barisal & $10 \cdot 9$ & $-1 \cdot 8$ & $10 \cdot 9$ & $-2 \cdot 2$ \\
\hline Chittagong & $21 \cdot 3$ & -1.9 & $21 \cdot 4$ & $-2 \cdot 0$ \\
\hline Dhaka & $21 \cdot 8$ & $-1 \cdot 8$ & $21 \cdot 8$ & $-2 \cdot 0$ \\
\hline Khulna & $13 \cdot 4$ & $-1 \cdot 6$ & $13 \cdot 4$ & $-1 \cdot 6$ \\
\hline Rajshahi & $19 \cdot 4$ & $-1 \cdot 8$ & $19 \cdot 3$ & $-1 \cdot 8$ \\
\hline Sylhet & $13 \cdot 2$ & -1.9 & $13 \cdot 2$ & $-2 \cdot 0$ \\
\hline
\end{tabular}

SES, socio-economic status.

availability of community health and education services, community employment and social participation and level of community education. All trends were statistically significant $(P$-trend $<0 \cdot 001)$.

\section{Variation attributable to communities}

Figure 2 shows the amount of variation in child weightand height-for-age that was attributed to communities in our sample, in the unconditional model (model 1) and in the models adjusted for individual- (model 2) and community-level covariates (model 3). Geographical 
(A)

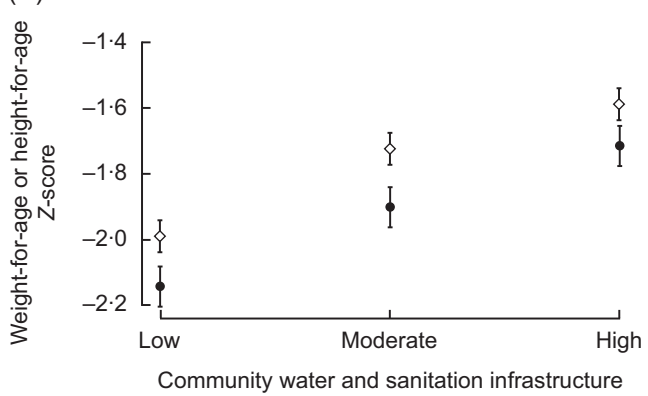

(C)

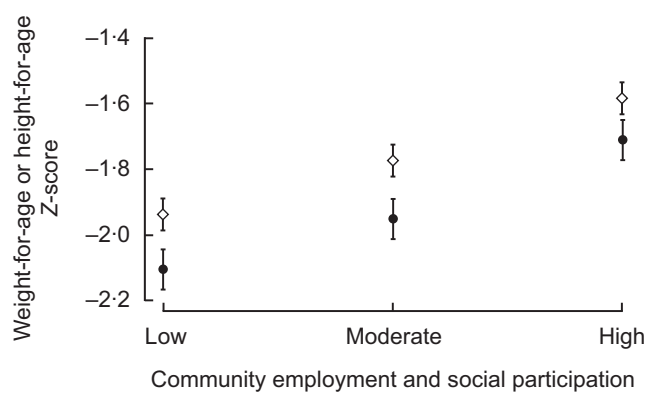

(B)

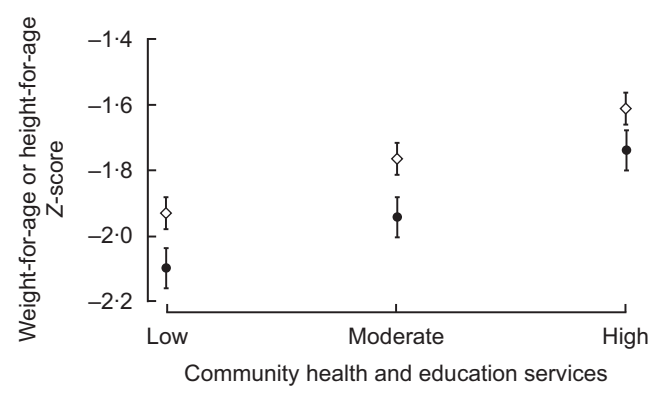

(D)

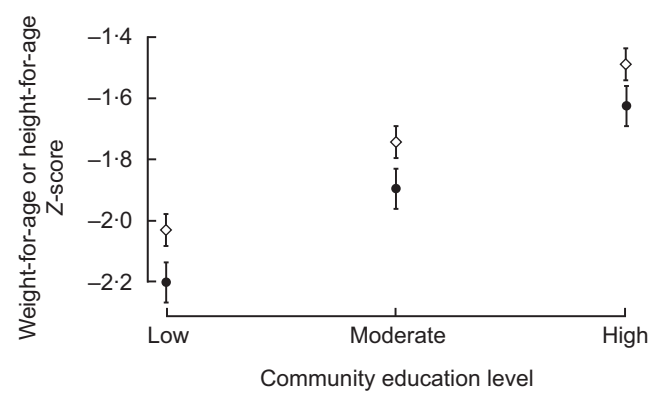

Fig. 1 Mean weight-for-age $(\diamond)$ and height-for-age $(\bullet)$ of Bangladeshi children aged 0-59 months across low, moderate and high levels of assessed community characteristics: community water and sanitation infrastructure (A), community health and education services (B), community economic and social participation (C) and level of community education (D). All trends were statistically significant $(P$-trend $<0 \cdot 001)$

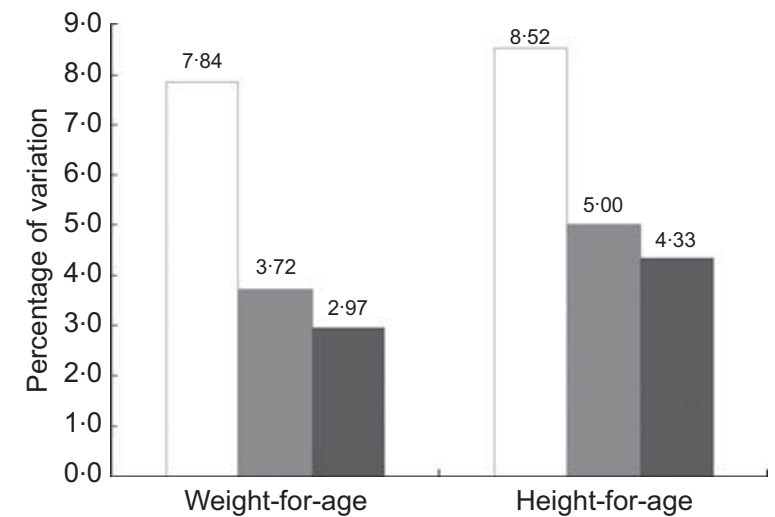

Fig. 2 Percentage of variation attributed to communities for child weight-for-age and height-for-age before (model $1, \square$ ) and after (model $2, \square$ ) adjusting for individual-level covariates and after adjusting for community-level environmental characteristics and individual-level covariates (model 3 ,

Note: The proportion of variation attributable to communities was calculated as the 'intra-class correlation'(48). The model adjusted for maternal and child covariates (model 2, $\square$ ) included child's age, gender, preceding birth interval, early breast-feeding, recent illness, mother's age at childbirth, mother's BMI, mother's and father's level of education, household socio-economic status and household food security. The final model (model $3, \square$ ) included community environmental characteristics under study (community water and sanitation infrastructure, community health and education services, community economic and social participation and level of community education) and was adjusted for community-level covariates ('type of community': urban centre, small city, town, rural village and 'geographic division': Barisal, Chittagong, Dhaka, Khulna, Rajshahi or Sylhet) and all individual-level covariates (between-community) variation in the unconditional model accounted for $7 \cdot 8 \%$ and $8.5 \%$ of the total variation in child weight-for-age and height-for-age, respectively. The model adjusted for individual-level covariates explained roughly half (53\%) of the between-community variation in weight-for-age and slightly less than half ( $41 \%$ ) of the height-for-age variation. In model 3, which added community-level characteristics, the remaining variation was further reduced by $20 \%$ for weight-for-age and $13 \%$ for height-for-age, indicating the importance of the community environmental context in further explaining between-community variation beyond individual variables alone. Community-level variation in child nutritional status remained statistically significant in all models.

\section{Community characteristics associated witb child mutritional status}

Table 2 presents point estimates, SE and 95\% CI for each community characteristic from multilevel regressions of child weight-for-age and height-for-age (models 4A-D, $5 \mathrm{~A}-\mathrm{D}$ and 6 ). The upper third of this table presents unadjusted associations between each community characteristic and child weight-for-age and height-for-age from four multilevel models (models 4A-D). These models find that all levels of community characteristics are positively associated with child nutritional status (weight-for-age and height-for-age). In the middle third of Table 2 , models for each community-level characteristic adjusted for individuallevel covariates are presented (models 5A-D). The addition 
Table 2 Estimates, SE and $95 \% \mathrm{Cl}$ for community-level environmental characteristics derived from multilevel regressions of child weightfor-age and height-for-age $v$. community-level characteristics and covariates

\begin{tabular}{|c|c|c|c|c|c|c|}
\hline & \multicolumn{3}{|c|}{ Weight-for-age } & \multicolumn{3}{|c|}{ Height-for-age } \\
\hline & $\beta$ & SE & $95 \% \mathrm{Cl}$ & $\beta$ & SE & $95 \% \mathrm{Cl}$ \\
\hline \multicolumn{7}{|l|}{ Model $4(A-D)^{*}$} \\
\hline \multicolumn{7}{|c|}{ A. Community water and sanitation infrastructure } \\
\hline High & $0 \cdot 40$ & 0.05 & $0.30,0.51$ & 0.44 & 0.07 & $0.31,0.58$ \\
\hline Moderate & $0 \cdot 25$ & 0.05 & $0 \cdot 16,0.36$ & 0.24 & 0.07 & $0.11,0.36$ \\
\hline \multicolumn{7}{|c|}{ B. Community health and education services } \\
\hline High & $0 \cdot 31$ & 0.06 & $0.20,0.41$ & 0.36 & 0.07 & $0.23,0.49$ \\
\hline Moderate & $0 \cdot 15$ & 0.05 & $0.05,0.25$ & $0 \cdot 14$ & 0.07 & $0.01,0.26$ \\
\hline \multicolumn{7}{|c|}{ C. Community employment and social participation } \\
\hline High & $0 \cdot 36$ & 0.06 & $0.24,0.47$ & 0.40 & 0.07 & $0.27,0.53$ \\
\hline Moderate & $0 \cdot 15$ & 0.05 & $0.05,0.25$ & $0 \cdot 16$ & 0.07 & $0.04,0.29$ \\
\hline \multicolumn{7}{|c|}{ D. Level of community education } \\
\hline High & 0.54 & 0.05 & $0.46,0.63$ & 0.56 & 0.06 & $0.45,0.68$ \\
\hline Moderate & $0 \cdot 28$ & 0.04 & $0 \cdot 19,0.37$ & $0 \cdot 30$ & 0.06 & $0 \cdot 18,0.41$ \\
\hline \multicolumn{7}{|l|}{ Model $5(A-D) \dagger$} \\
\hline \multicolumn{7}{|c|}{ A. Community water and sanitation infrastructure } \\
\hline High & $0 \cdot 13$ & 0.06 & $0.02,0.24$ & 0.20 & 0.07 & $0.06,0.34$ \\
\hline Moderate & $0 \cdot 12$ & 0.05 & $0.03,0.21$ & $0 \cdot 11$ & 0.06 & $-0.01,0.23$ \\
\hline \multicolumn{7}{|c|}{ B. Community health and education services } \\
\hline High & $0 \cdot 12$ & 0.06 & $0.00,0.24$ & $0 \cdot 17$ & 0.08 & $0.02,0.33$ \\
\hline Moderate & 0.08 & 0.04 & $-0.01,0.16$ & 0.06 & 0.06 & $-0.05,0.17$ \\
\hline \multicolumn{7}{|c|}{ C. Community employment and social participation } \\
\hline High & $0 \cdot 18$ & 0.07 & $0.05,0.32$ & $0 \cdot 19$ & 0.07 & $0.06,0.33$ \\
\hline Moderate & 0.05 & 0.06 & $-0.06,0.17$ & 0.05 & 0.06 & $-0.06,0 \cdot 16$ \\
\hline \multicolumn{7}{|c|}{ D. Level of community education } \\
\hline High & $0 \cdot 24$ & 0.06 & $0.12,0.36$ & 0.25 & 0.07 & $0 \cdot 12,0.38$ \\
\hline Moderate & $0 \cdot 17$ & $0 \cdot 06$ & $0.05,0.28$ & $0 \cdot 17$ & 0.06 & $0.07,0.29$ \\
\hline \multicolumn{7}{|l|}{ Model $6 \ddagger$} \\
\hline \multicolumn{7}{|c|}{ A. Community water and sanitation infrastructure } \\
\hline High & 0.04 & 0.06 & $-0.08,0.15$ & 0.09 & 0.08 & $-0.07,0.24$ \\
\hline Moderate & 0.06 & 0.05 & $-0.04,0.16$ & 0.03 & 0.07 & $-0 \cdot 10,0 \cdot 16$ \\
\hline \multicolumn{7}{|c|}{ B. Community health and education services } \\
\hline High & 0.06 & 0.06 & $-0.06,0.18$ & 0.09 & 0.09 & $-0.07,0.27$ \\
\hline Moderate & 0.05 & 0.05 & $-0.04,0.13$ & 0.02 & 0.06 & $-0 \cdot 09,0 \cdot 14$ \\
\hline \multicolumn{7}{|c|}{ C. Community employment and social participation } \\
\hline High & 0.06 & 0.06 & $-0.05,0.17$ & $0 \cdot 13$ & 0.07 & $0.00,0.26$ \\
\hline Moderate & -0.01 & 0.05 & $-0 \cdot 10,0.08$ & 0.02 & 0.06 & $-0 \cdot 10,0 \cdot 13$ \\
\hline \multicolumn{7}{|c|}{ D. Level of community education } \\
\hline High & $0 \cdot 21$ & 0.06 & $0.11,0.33$ & $0 \cdot 18$ & 0.07 & $0.03,0.33$ \\
\hline Moderate & $0 \cdot 14$ & 0.05 & $0.05,0.22$ & $0 \cdot 14$ & 0.06 & $0.02,0.25$ \\
\hline
\end{tabular}

*In model $4(A-D)$, one community-level environmental characteristic was modelled at a time (the lowest tertile is reference (not shown)), without adjustment for individual-level covariates.

tIn model 5 (A-D), one community-level environmental characteristic was modelled at a time, adjusting for the following individual-level covariates: child's age, gender, preceding birth interval, early breast-feeding, recent illness, mother's age at childbirth, mother's BMI, mother's and father's level of education, household socio-economic status and household food security. Models also adjusted for community-level covariates: (type of community: urban centre, small city, town, rural village; and geographic division: Barisal, Chittagong, Dhaka, Khulna, Rajshahi or Sylhet).

fln model 6 , the community-level environmental characteristics presented are mutually adjusted, with additional adjustment for all individual- and communitylevel environmental covariates (as in model 5).

of individual-level covariates to these models attenuated the associations between the community environment and child nutrition, although community water and sanitation infrastructure, level of community education, and the highest levels of community health and education services and community employment and social participation remained positively associated with weight-for-age (Table 2 , left side). The findings for the height-for-age outcome were largely similar. In the height-for-age models adjusted for individual-level covariates (Table 2, model 5A-D, right side), the highest level of community health and education services was found to be positive and statistically significant, although the moderate level of community sanitation infrastructure was not. In the lower third of Table 2, we present estimates and 95\% CI from multilevel models for weight-for-age and height-for-age adjusted for all community- and individual-level covariates (model 6). In these models, level of community education emerged as a strong independent predictor of child height-for-age (highest $v$. lowest tertile, $\beta=0 \cdot 18$ (SE 0.07); moderate $v$. lowest tertile $\beta=0 \cdot 14$ (SE $0 \cdot 06$ )) and weight-for-age (highest $v$. lowest tertile $\beta=0 \cdot 21$ (SE $0 \cdot 06$ ); moderate $v$. lowest tertile $\beta=0 \cdot 14$ (SE $0 \cdot 05$ )). In the height-for-age model, the highest tertile of community employment and social participation also emerged as significant compared with the lowest tertile $(\beta=0 \cdot 13$ (sE $0 \cdot 06$ ); Table 2 ). 


\section{Discussion}

The present study investigates the shared community environment as a determinant of child nutritional status in Bangladesh. We found that between-community variation in child weight-for-age and height-for-age was not completely accounted for by the distribution of child- and maternal-level correlates and risk factors. Although studies on the determinants of child nutrition in Bangladesh have traditionally focused on individual-level factors ${ }^{(31,53-56)}$, our research shows the potential independent influence of the community environment on the distribution of nutritional status among Bangladeshi children. This finding is further supported by demonstrated reductions in unexplained between-community variance in child nutritional status after adjustment for specific contextual variables measured at the community level. Examined associations between specific community characteristics and child nutritional status were found to be positive, although independent effects of community environmental variables were largely attenuated after accounting for individual-level covariates. Community education, however, remained a consistent and positive predictor of child nutritional status across all models, including fully adjusted models.

These findings provide public policy information on the potential benefits of targeting the community context, especially education, for the improvement of child nutrition. Our results are consistent with other recent studies in developing countries on the influence of shared residential context on child nutritional status ${ }^{(39,40,57)}$. Maternal education has long been established as having a positive effect on child nutrition, and recent evidence from India recognizes additional benefits of educated fathers, grandmothers and the community at large ${ }^{(58,59)}$. Children will likely benefit from residing in communities that are primarily literate and in which community-based approaches to the management of undernutrition (e.g. the promotion of breast-feeding and appropriate complementary foods) are emphasized $^{(60)}$. We noted a positive relationship between community employment/social participation and child nutritional status. One possible mechanism through which such an effect may operate has been suggested in a report from India, in which participation in micro-credit organizations was found to increase sharing of child-care-related knowledge between mothers ${ }^{(61)}$. Income-generating activities, development of social networks and increasing maternal economic autonomy have also been shown to contribute to health improvements ${ }^{(38,63)}$.

An important consideration of the study findings is that characteristics of the community environment such as levels of services and infrastructure may not be distributed randomly ${ }^{(63,64)}$. Development policies, programmes or other external factors may influence the distribution of certain facilities and services within communities with high (or low) socio-economic or health indicators, leading to an uneven distribution of resources across communities.
Uneven distribution of services and infrastructure may have implications on child and maternal nutrition and on national and sub-national nutrition programmes and policies. In addition, individuals may choose to live in certain communities on the basis of reputation or perceived levels of services and amenities. Although community-level variables were treated as exogenous in our analyses, we have controlled for the possibility of migration by excluding individuals who were not permanent residents of their community. Typically, women included in the analysis had resided in their communities for 12 years.

There are certain limitations of our study. The measures used in the present study to denote access and availability to facilities were based on self-reported distances that may be prone to error, although validation studies indicate good accuracy. In addition, the quality of services was not assessed in the BDHS community service availability questionnaire. This may have introduced some measurement error into the community health and education services availability variable, since quality of services is likely to be inconsistent across communities in this sample. In all analyses, significant between-community variation in child nutritional status remained unexplained, underscoring the need for further systematic research on the mechanisms operating at the community level that may influence child nutritional status. Potential mechanisms related to child nutrition that we could not examine within the BDHS include access, availability and price of food, as well as local transportation and safety ${ }^{(65)}$. Furthermore, the reliability of the observed coefficients on the community-level predictors studied is subject to unmeasured maternal, child or household covariates. These coefficients should be interpreted with the consideration that their effects may be proxies for uncontrolled covariates at individual and household levels. We found maternal BMI to be positively associated with child nutritional status, suggesting the importance of considering the health of the parents ${ }^{(66)}$.

In summary, our study suggests evidence for independent contextual variation in child nutrition in Bangladesh. Although prospective studies are required to fully understand the potential influence of the community environment on child nutritional status, we emphasize the importance of incorporating a community-based approach for research on preventive and treatment strategies for child undernutrition in developing countries.

\section{Acknowledgements}

The present research received no specific grant from any funding agency in the public, commercial or not-for-profit sectors. C.K.C. is supported by a Public Health (Sidney Sax) Overseas Fellowship co-funded by the National Health and Medical Research Council and National Heart Foundation of Australia. S.V.S. is supported by the National Institutes of Health Career 
Development Award (NHLBI K25 HL081275). The analysis was conducted entirely using public use secondary data sets with no access to identifiers. The authors have no conflict of interest to declare. D.J.C. planned the study and conducted statistical analyses with the collaboration of C.K.C. and S.V.S. All authors participated in interpretation of the data and writing the manuscript. D.J.C. acknowledges the instruction and guidance of Dr M Boyle, Dr K Georgiades, H Kyu and student colleagues participating in the course title Advanced Analysis of Survey Data at McMaster University.

\section{References}

1. Caulfield LE, Richard SA, Rivera JA et al. (2006) Stunting, wasting, and micronutrient deficiency disorders. In Disease Control Priorities in Developing Countries, 2nd ed., pp. 551-568 [DT Jamison, JG Breman, AR Measham et al., editors]. New York: Oxford University Press.

2. Black RE, Allen LH, Bhutta ZA et al. (2008) Maternal and child undernutrition: global and regional exposures and health consequences. Lancet 371, 243-260.

3. United Nations Children's Fund (2009) The State of the World's Children 2009: Maternal and Newborn Health. New York: UNICEF.

4. World Health Organization Multicentre Growth Reference Study Group (2006) World Health Organization Child Growth Standards: Length/Height-for-Age, Weight-for-Age, Weight-for-Length, Weight-for-Height, and Body Mass Index-for-Age: Methods and Development. Geneva: WHO.

5. Lanata CF \& Black RE (2001) Diarrheal and respiratory diseases. In Nutrition and Health in Developing Countries, pp. 139-178 [R Semba and M Bloem, editors]. Totowa, NJ: Humana Press.

6. Pelletier DL, Olson CM \& Frongillo EA Jr (2001) Food insecurity, hunger, and undernutrition. In Present Knowledge in Nutrition, 8th ed., pp. 701-713 [BA Bowman and RM Russell, editors]. Washington, DC: ILSI Press.

7. Victora CG (2009) Nutrition in early life: a global priority. Lancet 374, 1123-1125.

8. Grantham-McGregor SM (1995) A review of studies of the effect of severe malnutrition on mental development. J Nutr 125, 8 Suppl., 2233S-2238S.

9. Haas JD, Murdoc S, Rivera J et al. (1996) Early nutrition and later physical work capacity. Nutr Rev 54, 2 Pt 2, S41-S48.

10. Pollitt E, Gorman KS, Engle PL et al. (1993) Early supplementary feeding and cognition. Monogr Soc Res Child Dev 58, 1-122.

11. Victora CG, Adair L, Fall C et al. (2008) Maternal and child undernutrition: consequences for adult health and human capital. Lancet 371, 340-357.

12. Bryce J, Terreri N, Victora CG et al. (2006) Countdown to 2015: tracking intervention coverage for child survival. Lancet 368, 1067-1076.

13. Morris SS, Cogill B \& Uauy R (2008) Effective international action against undernutrition: why has it proven so difficult and what can be done to accelerate progress? Lancet 371 , 608-621.

14. Anon. (1978) Declaration of Alma-Ata. International Conference on Primary Health Care, USSR, 6-12 September.

15. Lawn JE, Rohde J, Rifkin S et al. (2008) Alma-Ata 30 years on: revolutionary, relevant, and time to revitalise. Lancet 372, 917-927.

16. Morley D, Rohde J \& Williams G (1983) Practising Health for All. Oxford: Oxford University Press.
17. Walsh JA \& Warren KS (1980) Selective primary health care: an interim strategy for disease control in developing countries. Soc Sci Med Med Econ 14, 145-163.

18. de Onis M, Blossner M \& Villar J (1998) Levels and patterns of intrauterine growth retardation in developing countries. Eur J Clin Nutr 52, Suppl. 1, S5-S15.

19. Menezes AM, Hallal PC, Santos IS et al. (2005) Infant mortality in Pelotas, Brazil: a comparison of risk factors in two birth cohorts. Rev Panam Salud Publica 2005 18, 439-446.

20. Christian P, West KP, Khatry SK et al. (2003) Effects of maternal micronutrient supplementation on fetal loss and infant mortality. Am J Clin Nutr 78, 1194-1202.

21. Kramer MS (1987) Determinants of low birth weight: methodological assessment and meta-analysis. Bull World Health Organ 65, 663-737.

22. Semba RD \& Victora CG (2001) Low birth weight and perinatal mortality. In Nutrition and Health in Developing Countries, pp. 63-86 [R Semba and M Bloem, editors]. Totowa, NJ: Humana Press.

23. West KP Jr (2002) Extent of vitamin A deficiency among preschool children and women of reproductive age. J Nutr 132, Suppl. 9, 2857S-2866S.

24. Lopez AD, Mathers CD, Ezzati M et al. (2006) Global Burden of Disease and Risk Factors. New York: Oxford University Press.

25. Brown KH, Wuehler SE \& Peerson JM (2001) The importance of zinc in human nutrition and estimation of the global prevalence of zinc deficiency. Food Nutr Bull 22, 113-125.

26. Kraemer K \& Zimmermann MB (editors) (2007) Nutritional Anemias. Basel: Sight and Life.

27. Rowland MG, Rowland SG \& Cole TJ (1988) Impact of infection on the growth of children from 0 to 2 years in an urban West African community. Am J Clin Nutr 47, 134-138.

28. Assis AM, Barreto ML, Santos LM et al. (2005) Growth faltering in childhood related to diarrhea: a longitudinal community based study. Eur J Clin Nutr 59, 1317-1323.

29. Frongillo EA Jr, de Onis M \& Hanson KM (1997) Socioeconomic and demographic factors are associated with worldwide patterns of stunting and wasting of children. J Nutr 127, 2302-2309.

30. Gopalan S (2000) Malnutrition: causes, consequences, and solutions. Nutrition 16, 556-558.

31. Rahman A, Chowdhury S, Karim A et al. (2008) Factors associated with nutritional status of children in Bangladesh: a multivariate analsis. Demogr India 37, 95-109.

32. Terra de Souza AC, Peterson KE, Andrade FM et al. (2000) Circumstances of post-neonatal deaths in Ceara, Northeast Brazil: mothers' health care-seeking behaviors during their infants' fatal illness. Soc Sci Med 51, 1675-1693.

33. Marmot M (2007) Achieving health equity: from root causes to fair outcomes. Lancet 370, 1153-1163.

34. Haines A, Sanders D, Lehmann U et al. (2007) Achieving child survival goals: potential contribution of community health workers. Lancet 369, 2121-2131.

35. Smith LC \& Haddad LJ (2000) Explaining Child Malnutrition in Developing Countries: A Cross-Country Analysis. Washington, DC: International Food Policy Research Institute.

36. Smith LC \& Haddad LJ (2000) Overcoming Child Malnutrition in Developing Countries: Past Achievements and Future Choices. Washington, DC: International Food Policy Research Institute.

37. United Nations Children's Fund (1991) Strategy for Improved Nutrition of Children and Women in Developing Countries: UNICEF Policy Review. New York: UNICEF.

38. Griffiths P, Madise N, Whitworth A et al. (2004) A tale of two continents: a multilevel comparison of the determinants of child nutritional status from selected African and Indian regions. Health Place 10, 183-199. 
39. Pongou R, Ezzati M \& Salomon JA (2006) Household and community socioeconomic and environmental determinants of child nutritional status in Cameroon. BMC Public Health 6, 98.

40. Uthman OA (2009) A multilevel analysis of individual and community effect on chronic childhood malnutrition in rural Nigeria. J Trop Pediatr 55, 109-115.

41. Subramanian SV, Glymour M \& Kawachi I (2007) Identifying causal ecologic effects on health: potentials and challenges. In Macrosocial Determinants of Population Health, pp. 301-331 [S Galea, editor]. New York: Springer Media.

42. National Institute of Population Research and Training, Mitra and Associates \& ORC Macro (2005) Bangladesh Demographic and Health Survey 2004. Dhaka and Calverton, MD: NIPORT, Mitra \& Associates, \& ORC Macro.

43. Wilkinson MI, Njogu W \& Abderrahim N (1993) The Availability of Family Planning and Maternal and Child Health Services. Columbia, MD: Macro International Inc.

44. Subramanyam MA, Kawachi I, Berkman LF et al. (2010) Socioeconomic inequalities in childhood undernutrition in India: analyzing trends between 1992 and 2005. PLoS One 5, e11392.

45. Rutstein SO \& Johnson K (2004) The DHS Wealth Index. DHS Comparative Reports no. 6. Calverton, MD: ORC Macro.

46. Filmer D \& Pritchett LH (2001) Estimating wealth effects without expenditure data - or tears: an application to educational enrollments in states of India. Demography $\mathbf{3 8}$, 115-132.

47. Barros AJ \& Victora CG (2005) A nationwide wealth score based on the 2000 Brazilian demographic census. Rev Saude Publica 39, 523-529.

48. Subramanian SV, Jones K \& Duncan C (2003) Multilevel methods for public health research. In Neighborbods and Health, pp. 65-111 [I Kawachi and LF Berkman, editors]. New York, NY: Oxford University Press.

49. Goldstein H (2003) Multilevel Statistical Models. London: Arnold.

50. Raudenbush S \& Bryk A (2002) Hierarchical Linear Models: Applications and Data Analysis Methods. Thousand Oaks, CA: Sage Publications.

51. Rasbash J, Browne WJ, Healy M et al. (2010) MLwiN Version 2.20. Bristol, UK: Centre for Multilevel Modelling, University of Bristol.

52. Gelman A \& Hill J (2007) Data Analysis Using Regression and Multilevel/Hierarchical Models. New York: Cambridge University Press.
53. Bairagi R \& Chowdhury MK (1994) Socioeconomic and anthropometric status, and mortality of young children in rural Bangladesh. Int J Epidemiol 23, 1179-1184.

54. Das S, Hossain MZ \& Islam MA (2008) Predictors of child chronic malnutrition in Bangladesh. Proc Pakistan Acad Sci 45, 137-155.

55. Hong R, Banta JE \& Betancourt JA (2006) Relationship between household wealth inequality and chronic childhood under-nutrition in Bangladesh. Int J Equity Health $\mathbf{5}, 15$.

56. Hussain TM \& Smith JF (1999) The relationship between maternal work and other socioeconomic factors and child health in Bangladesh. Public Health 113, 299-302.

57. Fotso JC (2006) Child health inequities in developing countries: differences across urban and rural areas. Int $J$ Equity Health 5, 9.

58. Frost MB, Forste R \& Haas DW (2005) Maternal education and child nutritional status in Bolivia: finding the links. Soc Sci Med 60, 395-407.

59. Moestue H \& Huttly S (2008) Adult education and child nutrition: the role of family and community. $J$ Epidemiol Community Health 62, 153-159.

60. Bhutta ZA, Ahmed T, Black RE et al. (2008) What works? Interventions for maternal and child undernutrition and survival. Lancet 371, 417-440.

61. Moestue H, Huttly S, Sarella L et al. (2007) 'The bigger the better' - mothers' social networks and child nutrition in Andhra Pradesh. Public Health Nutr 10, 1274-1282.

62. Macintyre S \& Ellaway A (2000) Ecological approaches: rediscovering the role of the physical and social environment. In Social Epidemiology, pp. 332-348 [LF Berkman and I Kawachi, editors]. New York: Oxford University Press.

63. Rosenzweig MR \& Wolpin KI (1986) Evaluating the effects of optimally distributed public programs: child health and family planning interventions. Am Econ Rev 76, 470-482.

64. Sastry N (1996) Community characteristics, individual and household attributes, and child survival in Brazil. Demography 33, 211-229.

65. Chow CK, Lock K, Teo K et al. (2009) Environmental and societal influences acting on cardiovascular risk factors and disease at a population level: a review. Int J Epidemiol 38, $1580-1594$.

66. Subramanian SV, Ackerson LK \& Smith GD (2010) Parental BMI and childhood undernutrition in India: an assessment of intrauterine influence. Pediatrics 126, e663-e671. 